\title{
Los Sorias y la escritura como guerra: temporalidad y mundos posibles en la poética de Alberto Laiseca*
}

Fecha de recepción: 05 de septiembre de 2015

Fecha de aprobación: 01 de abril de 2016

\section{Resumen}

En este trabajo analizaremos los modos a través de los cuales la representación de la guerra atraviesa los diferentes niveles textuales de Los sorias, la novela central de Alberto Laiseca y una de las más relevantes de la literatura argentina contemporánea. Haciéndose eco de la fuerte pregnancia cultural de lo bélico en la literatura argentina, veremos cómo gran parte del efecto de canonización de la obra de Laiseca se sustenta en el modo en que estructura los "mundos posibles" de su poética a través de la guerra ya no sólo como tema, sino como principio escriturario y como estrategia para establecer una particular distribución de la temporalidad narrativa. posibles.

Palabras clave: Laiseca, guerra, temporalidad, mundos

Citar: Conde de Boeck, J.A. (enero-junio de 2016). Los Sorias y la escritura como guerra: temporalidad y mundos posibles en la poética de Alberto Laiseca. La Palabra, (28), 105-126. doi: http://dx.doi.org/10.19053/01218530.4791
José Agustín Conde de Boeck Universidad Nacional de Tucumán Licenciado en Letras por la Universidad Nacional de Tucumán. Doctorando en Letras Universidad Nacional de Córdoba. josecondeboeck@hotmail.com

* Artículo de reflexión producto de investigación doctoral titulado "Coloquialidad, discurso y transgresión: el caso de la revista Babel (1988-1991)" desarrollado en la Universidad Nacional de Tucumán y financiada por CONICET. 


\title{
la palabra
}

\section{Los Sorias [The Sorias] and Writing as War: Temporality and Possible Worlds in the Poetics of Alberto Laiseca}

\begin{abstract}
In this paper we will analyze the ways in which the representation of war crosses diverse textual levels in Los sorias [The Sorias], Alberto Laiseca's main novel, and one of the most relevant in Argentine contemporary literature. Adressing the strong cultural importance of the war in Argentine literature, we will examine the relationship between the effect of canonization in Laiseca and the war structure of his "possible worlds". And we will consider war not just as a literary topic, but as a writing principle and strategy for establishing a particular narrative temporality.
\end{abstract}

Keywords: Laiseca, war, temporality, possible worlds.

\section{Les Sorias et l'écriture comme guerre : temporalité et mondes possibles dans la poétique d'Alberto Laiseca}

\section{Résumé}

Dans ce travail nous analyserons les modes de représentation de la guerre qui traversent les différents niveaux textuels des Sorias, le roman central d'Alberto Laiseca (un des plus importants de la littérature argentine contemporaine). Etant donné la présence culturelle de la guerre dans la littérature argentine on verra comment l'effet de " canonisation" de l'œuvre de Laiseca est soutenu, en grande partie, dans la manière comme il structure les " mondes possibles" de sa poétique à travers la guerre non seulement comme sujet, mais comme principe d'écriture et comme stratégie de distribution de la temporalité narrative.

Mots clés : Laiseca, guerre, temporalité, mondes possibles. 
De cualquier manera un día tuve sobre mi mesa la obra. Era un libro de tapas duras y negras, sin inscripciones exteriores, de unas setecientas páginas. El único ejemplar. Lo abrí y ni yo podía creer que hubiese escrito eso. Qué se habían hecho de los bloqueos. Dónde estaban mis imitaciones de Hermann Hesse. [...] La obra maestra era ética, estética, mística y práctica. Alberto Laiseca, "Gracias Chanchúbelo" (2011, p. 221)

\section{Introducción}

En El país de la guerra (2014), Martín Kohan analiza el papel de la guerra como tema hegemónico en las narraciones argentinas acerca de la historia nacional, o más bien, la intervención del imaginario de la guerra en la construcción de la identidad argentina. Según Kohan, la historia nacional, aun en los tiempos de paz, se busca a sí misma en la épica de la guerra. A través de una serie de textos -desde Alberdi, Mitre y Sarmiento hasta la ficcionalización de la Guerra de Malvinas en las novelas de Fogwill y Gamerro, pasando por los años setenta y su concepción de la lucha armada como guerra asimétrica en Walsh y UrondoKohan postula la imposibilidad de pensar la construcción de la historia argentina por fuera de un cierto relato de guerra que se inaugura en el siglo XIX y se proyecta hasta la actualidad.

La guerra como isotopía hegemónica de la literatura nacional se postularía como un verdadero "paradigma de argentinidad", configurado en términos de efectos narrativos: modos de narrar, disposición de personajes, jerarquías de planos de escenificación, etc. (Zunini, 2014). En cierta medida, la obra de Laiseca, con Los sorias (1998) en su centro, es una puesta en escena definitiva de la guerra como significante: la guerra como "continuación de la política por otros medios" (frase de Clausewitz que vuelve de manera recurrente en el ensayo de Kohan), la guerra total -surrealista, delirante, exóticadesde una concentración plástica de formas muy específicas de la guerra como relato nacional: una simbolización hiperbólica y sublimada de la guerra como constante punto de partida en toda definición de la argentinidad. Porque, precisamente, Laiseca busca fundar la "novela total" de la literatura nacional en el vértice de una guerra donde toda remisión a la argentinidad es elidida de forma tal que termina configurando un énfasis.

El objetivo de este trabajo se concentrará en analizar el modo en que la tematización de la guerra confiere densidad narrativa a la obra de Laiseca, tanto en la configuración de los niveles de temporalidad del relato, como en la particular construcción de un mundo literario que se erige en toda una mitología autónoma. Para ello utilizaremos especialmente el concepto de heterocósmica o mundos posibles, desarrollado por Lubomír Dolezel (1998), y pondremos énfasis, a partir del análisis de los diferentes niveles que componen la obra (desde el cultural y editorial hasta el narrativo), en la noción típicamente laisequeana de "guerra total".

Hipergrafía, prolificidad, extensión

Haciendo referencia a la complejidad y extensión del Ulysses de James Joyce, la mítica novela cuyo relato abarca la temporalidad de un solo día en la vida de Stephen Dedalus y Leopold Bloom, Borges escribe en un poema que homenajea al autor irlandés: "Dame, Señor, coraje y alegría / para escalar la cumbre de este día".

Del mismo modo, acerca de la extensión de Los sorias, Ernesto Mallo confesaba:

En la primera página hay una cita de Almanzor que refiere que el mundo está sostenido por cuatro cosas. Una de ellas es el coraje de los valientes. No leí 
Los sorias, pero está en mi biblioteca a la espera de que algún día tenga el coraje de enfrentar sus más de 1.300 páginas. (Zina, 2011)

Sin embargo, la hipergrafía como rasgo fundamental de la poética desmesurada de Laiseca es un fenómeno que va más allá de la prolificidad (como sucede con Aira) o de la extensión (como puede señalarse en obras como El pasado de Pauls, Vivir afuera de Fogwill, El traductor de Benesdra, Las islas de Gamerro o La Historia de Caparrós). La hipergrafía laisequeana es la materialidad de su escritura: es precisamente su movimiento expansivo (es decir, la distorsión y la amplificación) lo que produce el "efecto Laiseca", e incluso es lo que da lugar a la actitud de culto entre los autores más jóvenes (el realismo delirante tiene la iteratividad de un ritual).

Sobre la extensión de algunas novelas de la literatura argentina actual, y en particular sobre $E l$ pasado de Alan Pauls, Sarlo (2007) afirma:

La extensión de El pasado es $[\ldots]$ su presupuesto. La novela no "salió" larga, como resultado de una impericia, sino que, para ser lo que es, necesitó ser larga. Sería un error pensar que algo "está de más", cuando, en realidad, esa demasía sostiene el carácter mismo del texto. La extensión fue un programa, no una consecuencia. (p. 448).

Parecería lógico enmarcar las grandes novelas de Laiseca (El jardín de las máquinas parlantes y Los sorias) en este mismo diagnóstico, y, sin embargo, no dejaría de resultar extraño al sistema de procedimientos propios del autor, al conjunto de recursos con que ha construido su posición marginal en el campo literario. Decir que la extensión de Los sorias es un "programa" iría a trasmano del "plebeyismo" que configura prácticamente la génesis escrituraria de la literatura de Laiseca y la estrategia fundamental de su inserción en el campo literario.

Es justamente esta sensación de texto salvaje, expansivo y arbitrario lo que configura el efecto de Los sorias: la sensación que tiene el lector, cercana a la que experimenta el lector de Kafka, de que la novela podría extenderse ad aeternum, por inserción y acumulación de episodios, por expansión analítica de sus imágenes. A diferencia de 10 que sucede con El pasado, sí puede (y debe) decirse acerca de las novelas de Laiseca que "salieron" largas como resultado de una "impericia". Pero es que es esta "impericia", este efecto de descuido, de "mala escritura", lo que coloca al realismo delirante (como lo ha bautizado el propio autor) en esa posición de verdadera (y no meramente promocionada) inclasificabilidad. Lo incómodo de Los sorias es, precisamente, su falta de programa, su arbitrariedad que intenta emular la pluralidad del mundo. Esa falta de literariedad con que su demasía parece expandirse frenéticamente, como si todo pudiera "estar de más", por superposición de episodios, por expansión descriptiva, por un desborde "anormal" de imaginación. La construcción de Laiseca como autor postmoderno, así como la pregnancia que tuvo su recepción en un espacio más o menos coincidente con el de César Aira, se basa en la puesta en escena de un valor: la hipergrafía como compulsión que denuncia el consecuencialismo y el régimen representativo de la literatura de "programa", de la producción literaria calibrada por un discurso que le es exterior. Con justicia, Guillermo Saavedra presentaba a Laiseca, en 1987, como "alguien capaz de escribir olímpicamente de espaldas a los usos y costumbres del circuito local".

Igualmente, no será en la prolificidad (auto-canonización por saturación del mercado) donde pueda comprenderse la apertura receptiva que la obra de César Aira significó para la de Laiseca (Prieto, 2006, p. 446), sino más bien en la asunción de una escritura "surrealista" hasta sus últimas consecuencias, aún cuando implique la disolución de los límites entre literatura "buena" 

En todo caso, la inclusión de Los sorias en un tríptico junto a El jardín y a El gusano máximo de la vida misma (1999) sería, a todas luces, una clasificación artificial a resultas de los efectos producidos en el campo literario argentino según el orden de publicación de las obras. Igualmente, si el efecto de recepción de Los sorias al ser publicada en 1998 es el de culminación de un proyecto creador, en términos de producción debería hablarse más bien de punto de partida. Ahora bien, si pensamos que todas las obras de Laiseca remiten explícita o implícitamente a su novela mayor, la cual se erige en centro gravitatorio de su poética, esta duplicidad (culminación/punto de partida) genera a su vez un efecto rizomático ${ }^{3}$, donde la referencia a Los sorias nunca es lineal (antecedencia/ posterioridad), sino accidentada (una obra que existe y que no existe a la vez; culminada, pero inédita) y ubicua (Los sorias como omnipresencia a lo largo de todo el programa literario de su autor); un efecto de rizoma donde, a fuerza de paradoja, Los sorias no constituye un centro jerárquico que subordina al resto de las obras, sino que es la multiplicidad de todas ellas.

Instancias de mediación editorial

La historia de Los sorias en el campo literario argentino es tan mítica como accidentada. Si bien se mantuvo durante los años ochenta y noventa como una suerte de obra maestra secreta e inédita en el ámbito intelectual, las continuas redacciones (de las cuales sólo la cuarta llegó a ser la definitiva) y los constantes intentos frustrados de publicarla produjeron la construcción de un fuerte efecto de sentido alrededor de la novela, el cual, como hemos visto, cristaliza completamente en el discurso mítico que se manifiesta en el prólogo de Piglia a la primera edición, o en algunas declaraciones de Fogwill y Aira. Durante los años ochenta y noventa se publicaron algunos fragmentos de la gran novela "impublicable" (en el semanario El Porteño, en $V$ de Vian, en Babel) y la leyenda circuló por el ambiente literario a través de la lectura de los ciclópeos manuscritos originales, proporcionados por el propio autor (Piglia, Fogwill y Aira fueron los primeros lectores de la obra).

Finalmente se publicó en 1998 , de la mano de Gastón Gallo, director de la naciente editorial Simurg, y fueron necesarios numerosos voluntarios para tipear los manuscritos (Zina, 2011). La primera edición, en papel biblia, e ilustraciones típicamente laisequeanas (mapas, diseños, pentagramas, etc.), circuló en una edición limitada de trescientos cincuenta ejemplares.
Recién en 2004, Los sorias se reeditó en una impresión de mayor tirada (mil quinientos ejemplares), esta vez a través de la editorial Gárgola, dirigida por Ricardo Romero. En 2014, diez años más tarde, Simurg se encargó de la tercera edición de la novela, poco después de que apareciera en Francia la primera traducción de alguna obra del autor: Aventures d'un romancier atonal, publicada por la editorial El Nuevo Attila y traducida por Antonio Werli (también se han presentado en 2014, en el Salón del Libro de París, los relatos "Yo comí una chuleta de Napoleón" y "Mi mujer", publicados por La Guêpe Cartonnière).

\section{Género cultural y antecedentes} en el campo

Frente al proyecto creador de Laiseca, y particularmente frente a su centro medular, Los sorias, es inevitable remitir a esa recuperación de una "vanguardia" fuerte que comenzó a emerger con los autores de Literal a comienzos de los años setenta: la búsqueda de una revolución literaria a partir de una suerte de terrorismo de los procedimientos hegemónicos de lo literario, la impugnación de la mera representación lineal de la realidad, el rechazo a caer en los compromisos sociales sistemáticos y su reivindicación de lo imaginario como un "envolvente de la realidad”, como dice Germán García

Tomando el concepto de rizoma de Deleuze y Guattari (1972). 
en su posfacio a El fiord (1969, p. 43). En continuidad, también resulta inevitable la remisión al género de la novela experimental, desde sus antecedentes universales, como Ulysses de Joyce, las obras lúdicas de Raymond Roussel o el movimiento surrealista, hasta su refundación en las letras nacionales con Marechal, Macedonio Fernández, Filloy y Cortázar. Experimentación con el lenguaje y utilización del humor como recurso para exponer una visión del mundo propia son elementos que Los sorias comparte con cierta forma de la novela vanguardista argentina que tiene a Joyce como asignatura pendiente y que en Adán Buenosayres, en Rayuela o en Museo de la novela de la Eterna asume la tarea paradójica de, en un único gesto, destruir la novela como género $\mathrm{y}$, a la vez, construir la "gran novela total". En este marco de búsquedas estéticas, "la idea wagneriana de un arte total adquiere con Laiseca forma de novela" (Link, 1998).

La crítica se ha hecho eco en numerosas ocasiones de esta necesidad de explicar el realismo delirante de Laiseca por medio de su inclusión en el paradigma de las novelas vanguardistas argentinas (Piglia, 2004; Bergara,
2013; Vázquez, 2008; Kurlat Ares, 2006). La con-tratapa de Su turno en la edición de Mansalva, por ejemplo, afirma de manera taxativa:

Su turno -parodia de la novela policial y de la gótica, donde el lenguaje y la invención se funden en la pura acción del relato- vuelve comprensible el linaje que posteriormente protagonizó una de las líneas más potentes en la construcción de la literatura argentina de vanguardia. (2010).

Y, sin embargo, en la representación que Laiseca hace del arte, su repudio a las vanguardias, a las que identifica con el arte abstracto, se presenta de manera evidente, especialmente en obras como Por favor, iplágienme! o en su novelización de El artista, así como en la crítica que hace en El jardín de las máquinas parlantes a sus propias juveniles veleidades vanguardistas (2013, 97-98). Así, por ejemplo, el autor afirma: "Cortázar me gusta en sus cuentos, pero creo que en sus novelas se dejó llevar por la vanguardia y no fue tan bueno" (Mazzuco, 2010). Y si consideramos que, a fin de cuentas, Laiseca no ha tenido reparos en expresar su admiración por Marechal o Filloy, puede afirmarse que, en todo caso, es el intelectualismo estéril de las vanguardias lo que constituye el objeto de su rechazo, puesto que no puede negarse la continuidad de su obra con los experimentalismos de Lamborghini, Aira o Marcelo Fox. En esta línea reflexiona Daniel Link, al comparar Los sorias con Memorias de un semidiós de Héctor Libertella (que "pueden ser las novelas más larga y más corta de la literatura argentina" [1998]):

Tan lejos de la vanguardia como del realismo "de almacén”, Libertella y Laiseca definen su literatura con palabras como sueño y delirio. Sólo habría dos lógicas para tener en cuenta: la lógica del mito (aquello que se puede contar, pero que no puede interpretarse) hacia la que tiende Laiseca (y de ahí su interés, que no hay que confundir con ningún exotismo ${ }^{4}$, por las antiguas dinastías chinas y egipcias) y la lógica del sueño (aquello que no se puede contar, que debe inter-pretarse) en la que hace pie Libertella. ${ }^{5}$

\footnotetext{
4 Debemos aclarar que, si bien estamos de acuerdo con esta posición de Link, el sentido que nosotros concedemos al término "exotismo" en esta investigación se restringe a una noción más específica: lo exótico como construcción paródica, artificio simbólico y pastiche entre los géneros "altos" y "bajos" de la literatura, y, muy particularmente, con la tematización, propia de la novela moderna, de lo extranjero y de lo ajeno como significante estereotipado que remite inevitablemente a la propia identidad social y a la instancia de enunciación.

5 Link (1998) afirma luego, en torno a la novela de Libertella: "es previsible, pues, que al autor le sorprenda lo que sus lectores leen en sus libros. En cada interpretación, sabido es, aparece el propio fantasma. Y si el Semidiós es Yabrán eso es porque Yabrán, hoy, es el fantasma argentino". Esto mismo nos permite repensar las lecturas alegóricas que se han hecho
} 
Además del mito, la vanguardia y la novela experimental, debe tenerse en cuenta la frecuente relación que se establece entre Los sorias y géneros como la ciencia ficción (Piglia en Laiseca, 20036; Ravetti, 2013a), la novela gótica y de terror (aspecto fortalecido por el papel del autor en los mass media, como en sus presentaciones televisivas de cuentos de terror, y no tanto argumentado por la crítica, aunque el propio Laiseca resalta esta filiación de los referentes paródicos de sus obras -Poe, Stoker, Meyrinkque apuntan al género de terror), la fantasía épica (el propio Laiseca afirma que su novela puede leerse como "ficción pura", al estilo de Tolkien ${ }^{7}$ [en Petroselli, 2004]) o la novela de aventuras (así, Kurlat Ares [59] relaciona la emergencia de las novelas exóticas de Laiseca con una revitalización, en clave postmoderna, de la novela juvenil de aventuras: Arnulfo o los infortunios de un príncipe y La perla del emperador de Daniel Guebel, La noche anterior de Martín Caparrós, algunas novelas de Aira, etc., a lo cual podría incluirse, como extensiones hacia los noventa, Son del África de Sergio Bizzio y Un poeta nacional de C.E. Feiling, ambas de 1993).

\section{Algunas líneas generales de la superficie textual de Los sorias}

Son tres los paratextos fundamentales de Los sorias (más allá de las tres diversas portadas que han acompañado a sus sucesivas ediciones): el prólogo de Ricardo Piglia (que a su vez configura un metatexto crítico) ${ }^{8}$ y la dedicatoria al crítico de arte César Magrini (a quien Laiseca define, según lo que Oscar Wilde llamaba "el crítico como artista"). El tercer paratexto con que abre la novela, un epígrafe, es una cita adjudicada al caudillo árabe Almanzor:

El mundo está sostenido solamente por cuatro cosas: la ciencia de los sabios, la justicia de los grandes, la plegaria de los justos y el coraje de los valientes. (2004, p. 13)
Este paratexto remite a varios aspectos de la poética de Laiseca: la obsesión por la figura del tirano (Almanzor fue un caudillo musulmán que instauró un régimen totalitario en la España del siglo $\mathrm{X}$ ) y el interés por el exotismo oriental (así como Laiseca dedicó respectivas novelas al emperador chino ShiHuangdi con su construcción de la Gran Muralla y al faraón egipcio Kheops con su pirámide, no hubiera sido ajeno a sus intereses dedicar una obra a Almanzor y la construcción de su gran ciudad palacio de Almedina-al Zahira ${ }^{9}$ ). Ambos elementos serán centrales en Los sorias: la figura del dictador, encarnada en el Monitor, y la construcción ciclópea de monumentos simbólicos al estilo oriental (la escritura colosal de la propia novela funciona como construcción homóloga, introduciendo esa relación lúdica con que el autor se identifica a sí mismo con un Monstruo o con los propios tiranos de sus obras). A lo largo de la novela, se retoma el epígrafe cuando uno de los tiranos principales,

\footnotetext{
de la obra de Laiseca (Casas, 2014; a su vez, Kurlat Ares, 2006, es tal vez la síntesis perfecta de esta vertiente interpretativa), donde las torturas de Su turno son las de la triple A, o donde las dictaduras de Los sorias remiten al Proceso militar: lo político no como significado de la obra de Laiseca, sino como presencia fantasmática.

6 Contratapa de Las aventuras del profesor Eusebio Filigranati.

7 Abundan las comparaciones entre la epopeya total de Los sorias y la obra de J.R.R. Tolkien, El señor de los anillos. Excluyendo las obvias diferencias de género entre ambas obras y señalando los atributos paródicos de la obra de Laiseca, Christian Estrade (2013) afirma: "En otro orden de comparación Laiseca escribe una epopeya delirante, una versión sádica, ubuesca y criolla del El señor de los anillos de Tolkien”. En el Dictionnaire des Littératures Hispaniques compilado por Jordi Bonells (2009), se declara algo similar: "L'épopée politique tient de la farce rabelaisienne mais ne dédaigne pas, dans une sorte de parodie de Tolkien revisitée par Jarry [...]".

8 El prólogo de Ricardo Piglia es un metatexto de gran importancia en lo que respecta a la construcción de imagen de Laiseca en el campo literario y, en sí mismo, configura una instancia de canonización fundamental en la carrera del autor.

9 Puede mencionarse como curiosidad, acaso externa a las intenciones del autor, que la batalla donde fue vencido Almanzor, en Calatañazor, se encuentra en las cercanías de la ciudad de Soria (nombre que, como sabemos, en Los sorias no sólo tiene carácter de topónimo sino también de gentilicio, e incluso de adjetivo valorativo).
} 
el Soriator, plantea cambiar su nombre a Al-Manzur Billah, a fin de homenajear al personaje histórico (2004, p. 1067).

Asimismo, la enumeración cosmogónica de la cita de Almanzor evoca la ambición de totalidad que atraviesa todo el proyecto de Los sorias: la construcción de un mundo imaginario donde se describen las dinastías, las guerras, las costumbres religiosas, la literatura y el conocimiento de sus hiperbólicas civilizaciones. Por lo demás, la nota al pie donde Laiseca remite a la fuente de la cita -"Del artículo " $A$ mil años de Almanzor", de Miguel Albornoz (N. York Octubre de 1978. Diario La Prensa, Bs.As.)" (2004, p. 13)- funciona como un marcador, probablemente involuntario, del diletantismo con el cual el autor se construye como sujeto supuesto saber: a diferencia del saber borgeano, cuyo universo de referencias bibliográficas se sustenta en fuentes auténticas citadas o al menos consultadas en sus lenguas originales, Laiseca comienza su mayor obra con una cita tomada de un artículo de difusión proveniente de un diario local.
A su vez, el cuerpo textual de Los sorias está compuesto por 165 capítulos, número de cuya arbitrariedad puede inferirse el método acumulativo de su escritura, donde buena parte de sus macrosegmentos pueden leerse como relatos autoconclusivos y autónomos, al estilo de los compilados en Matando enanos a garrotazos (obra que, así como una miniatura de Los sorias, podría leerse también como un fragmento de sus métodos para construir su mundo narrado). Cada capítulo está introducido por un subtítulo que remite al personaje, al espacio o al objeto descripto, o bien a la situación narrada (cabe mencionar que un gran porcentaje de la novela, lo cual es característico en la poética del autor, está constituido por extensas descripciones): "El sótano de los corruptos y otros festines dignos de Atila", "Albergues para animales mágicos”, "La selva misteriosa", "Una civilización tan perfecta que ni ruinas deja", "Los tres chiflados (Shemp, Moe, Larry)". Muchos de estos subtítulos participan del humor absurdo que configura un elemento fundamental del realismo delirante.
EI narrador y el punto de vista

Usualmente omnisciente o cuasiominisciente, el punto de vista varía en la medida en que la novela abandona a Personaje Iseka (el protagonista en quien se centran los primeros capítulos) y se sitúa, ora en Monitor, ora en el Kratos Enrique Katel, o en otros personajes como Dionisios Iseka o Decamerón de Gaula (imposible hablar de actores ${ }^{10}$ secundarios en una narración tan sostenida por la proliferación de fragmentos y de relatos enmarcados, más aun teniendo en cuenta que la novela llega a tener más de un centenar de personajes). El uso del monólogo interior o del discurso indirecto libre produce en el narrador extradiegético, por medio de un segundo nivel narrativo, una constante internalización en la diégesis. Por momentos, el narrador en tercera persona permuta hacia una primera persona imprecisa, cuya función es más retórica o fática que diegética ("Pero no nos adelantamos", "Voy a consignar algunas frases de Juan Carlos Soria” [2004, p. 17]).

\footnotetext{
10 Nos remitimos al concepto de "actor" de Greimas: "término parosémico y sustitutivo del de personaje [...] designa, en correlación con el papel funcional del actante en el nivel semionarrativo o de la historia, las unidades léxicas nominalizadas que, operando ya en el plano discursivo, muestran la individualización como rasgo semántico y distintivo mínimo: el actor, pues, concuerda en gran medida con el personaje, aunque Greimas acepta que los actores pueden ser individuales o colectivos y figurativos (hombres o animales) o conceptuales (el azar)" (Valles Calatrava, 2008, p. 164). Siguiendo este concepto, podemos incluir entre los actores de Los sorias no sólo a los personajes figurativos e individuales (como Personaje Iseka, Monitor o el Kratos Enrique Katel), sino también a los actores colectivos (Tecnocracia, Soria, Protelia, Chanchín del Sur, y toda la cartografía geopolítica laisequeana) y conceptuales (las "manijas" enviadas por los esoteristas, el dios Exatlaltelico y, en definitiva, el Ser y el Anti-Ser). También pueden incluirse las diversas criaturas mágicas utilizadas por los esoteristas como medios para enfrentar a sus enemigos ("vurros", "harañas", "chimpanzés"). Estas criaturas, según el momento de la novela, actualizan diversas funciones, desde Aliado hasta Oponente.
} 
La novela abunda en relatos enmarcados (estructuras hipodiegéticas), desde el surrealista sueño del hombre de bronce, en el primer capítulo, pasando por constantes citas a la prensa tecnócrata, hasta las historias autónomas de una gran cantidad de personajes secundarios que no vuelven a mencionarse posteriormente. Incluso, vale repetirlo, los episodios a través de los cuales se desarrollan los personajes principales se presentan con cierta independencia unos de otros, generando un efecto acumulativo cercano al de los relatos de Matando enanos a garrotazos.

A diferencia de El jardín de las máquinas parlantes, que, más allá de hipodiégesis y digresiones, es una novela puramente narrativa y lineal, Los sorias sustenta su extensión y barroquismo en su privilegio del fragmento y la descripción. Es más, gran parte del universo construido en Los sorias, al dejar parcialmente de lado la diégesis inicial protagonizada por Personaje Iseka, se construye como una etnografía de cada aspecto de la mitología que funda: costumbres, religión, política, guerra, conspiraciones, fragmentos periodísticos, himnos, poemas, obras de teatro, etc. En esto puede emparentarse Los sorias con otra gran novela enciclopédica de la literatura argentina de los noventa: La Historia (1999) de Martín Caparrós. Ahora bien, esta tendencia a la "heterocósmica" (para comenzar a utilizar el concepto de Lubomír Dolezel [1998]) por medio de descripciones expansivas, si bien es común a todo el realismo delirante, en su mayor novela cobra el estatuto de matriz: todo lo que pasa a nivel narrativo en Los sorias está subordinado a la descripción digresiva de perfiles singulares de este universo, erigiendo al protagonista y al lector en funciones de testigo. Ya Piglia nota, en su prólogo, esta inclinación hacia el estatismo perceptivo que predomina en la novela:

El que narra es objeto de una persecución y en lugar de huir trata de explicar lo que está sucediendo. (2004, p. 9)

Como ya hemos dicho, el fragmentarismo de Los sorias la acerca a una versión dilatada $a d$ nauseam de los relatos de Matando enanos a garrotazos; pero 10 importante es resaltar que este efecto de acumulación otorga una suerte de procedimiento creativo a la novela: la arbitrariedad de episodios, la imaginación aleatoria, el experimento inventivo, algo semejante a la ideal y siniestra máquina de narrar que imaginara Piglia en La ciudad ausente (1992). Bajo el régimen de tal utopía narrativa, es comprensible que Piglia haya considerado a Los sorias como "la mejor novela escrita en la Argentina desde Los siete locos" (p. 7).

Temporalidad mítica y Los sorias como "mundo posible"

Lubomír Dolezel (1999) concede una importancia fundamental al estudio de los "mundos posibles" que se construyen en la literatura. Tomando un término dieciochesco utilizado por la filosofía de Leibniz (y luego por Alexander Baumgarten), Dolezel denomina "heterocósmica" a las realidades paralelas, coherentes y homogéneas, que la literatura pone en escena. Para Dolezel, los "mundos posibles" construidos por la narrativa literaria son sistemas de hechos ficticios creados discursivamente a partir de una "fuente de autoridad" (Dolezel, 1980, pp. 11-12), la cual se produce desde la instancia enunciativa donde se sintetizan el narrador (o narradores), el autor implicado $\mathrm{y}$, en última instancia, el autor empírico. Estas tres instancias concentran en sí la autoridad para admitir o excluir elementos de sus mundos literarios, y cuanto mayor es la autonomía que esta realidad posee respecto de la mera mímesis, mayor será la autoridad detentada por el autor para dar sustento a su realidad ficcional. Todo mundo posible sería en sí mismo un sistema de verosimilitud cuya densidad ontológica mantiene relaciones semióticas complejas 

No va a ser fácil. Las horas de los sorias se infiltran a través de las zonas desmilitarizadas y se lanzan como kamikazes sobre mis posiciones. Me pongo a escribir y miles de minutos, que escupen sus ametralladoras pesadas, pican la tierra al lado de mi cama. Cerca de mí un ciego afecta comer un chocolatín y me larga el papelito plateado. Un minuto sin estallar. Hay que quitarle el detonador. Llamen a la cuadrilla desmontadora de minutos. (2004, p. 25).

Por otra parte, las referencias espaciales mezclan su dimensión referencial con connotaciones ambiguas, donde el mundo ficcional en que se encuentran Tecnocracia y Soria, entre otras potencias, a veces incorpora signos de "disonancia argentinizante" (como en la Norteamérica de Su turno, la China de $L a$ mujer en la muralla o la Tollán/ Buenos Aires de El jardín de las máquinas parlantes) que distorsionan los límites espaciales al perder densidad mimética: ¿se trata todo de un delirio de Personaje Iseka o de un mundo cuya verosimilitud ficcional interior es efectiva? ¿Se trata de una alegoría con nombres apócrifos que representa de manera cifrada la realidad nacional inmediata?

Siguiendo las características con las que Dolezel (1999) define los "mundos posibles", pueden identificarse algunas particularidades del realismo delirante en general y de Los sorias en particular. Según Dolezel, toda heterocósmica sería incompleta en la medida en que toda diégesis es un perfil, un fragmento, de un mundo posible total. Las obras recortan pequeñas porciones de ese mundo posible (así, nunca conocemos lo que ocurre en cada rincón de los mapas de Tolkien, ni la totalidad del contenido de la borgeana Encyclopedia de Tlön, ni el desenlace narrativo de las tres grandes novelas de Kafka: las obras eligen mostrar una parte de los mundos que construyen). Podría decirse que, como en un iceberg, la obra literaria fáctica es sólo la parte visible, y el potencial mundo posible a que da lugar es la parte sumergida e invisible. Esto hace del mundo posible una realidad inagotable, siempre posible de ser revisitada y expandida. El mundo ficcional de Laiseca, como toda heterocósmica, está incompleto: Los sorias es sólo un fragmento de ese mundo (como dice Piglia "Un fragmento de ese mundo atomizado ha llegado hasta nosotros" [p. 10]). Su nivel de completamiento es siempre aplazado, pues, si bien a nivel intratextual sus otras obras se sitúan en un mundo más o menos identificable con el de Los sorias, estas obras también lo expanden de forma tal que siempre hay más zonas incompletas, inexploradas, elididas. Así, por ejemplo, uno de los factores que más contribuye a la incompletitud de la heterocósmica laisequeana es la cronología, la puesta en escena de la temporalidad diegética: en su mundo, los hechos pseudohistóricos no se localizan temporalmente bajo el régimen de algún sistema identificable, como siglos, años, fechas. La cronología laisequeana depende de una temporalidad mítica y no posee otro calendario que el del devenir narrativo y el de las grandes secuencias sucesivas (antes de la guerra, durante, después; deshumanización del dictador/rehumanización; preparación para la guerra, desarrollo de la guerra, derrota, etc.). Es a través de este uso de la temporalidad que Laiseca eleva la guerra, no ya a una representación de referentes socio-históricos particulares, sino al estatuto de mito. Con una temporalidad arquetípica, cuyo flujo se adapta a la idea general de lo bélico (no una guerra, sino todas las guerras), la escritura de Laiseca se organiza en torno a la guerra como mundo autónomo, ajeno a referentes exteriores, sólo deudor de una mítica de lo bélico. Y es por medio de esta estrategia, una vocación de universalidad, que logra rozar las aristas más complejas y las tensiones más profundas de la realidad argentina: un distanciamiento simbólico de la coyuntura social que termina, sin embargo, reconduciendo hacia ésta.

La infinita diversidad de mundos posibles nunca es homogénea, aunque cada uno de ellos en su 

enfrentamientos bélicos y conspiraciones políticas que tienen como eje a la figura de Monitor; en Aventuras de un novelista atonal aparece ya una versión caricaturesca y desbocada de la guerra total (narrada en "La epopeya del rey Teobaldo"); las defensas mágicas que simbolizan las construcciones ciclópeas en $L a$ hija de Kheops y en La mujer en la muralla (la Gran Pirámide y la Gran Muralla china) parecen anticipar el advenimiento de grandes enfrentamientos entre las fuerzas del Bien y el Mal, donde el principal terreno de batalla será el simbólico-mítico; $\mathrm{y}$, tanto en el pseudo-ensayo Por favor, iplágienme! como en la enorme épica esoterista de El jardín de las máquinas parlantes, se introducen aspectos centrales en el universo de Los sorias: el funcionamiento de la magia en el mundo laisequeano, los bandos que se distribuyen entre las fuerzas del Ser y el Anti-Ser, el bestiario de criaturas sobrenaturales que la guerra utiliza como armamento fundamental, las formas de concebir el arte y su función en un régimen que, como remisión a la figura siniestra del Hitler, sintetiza dictador y artista en una misma figura.

Ahora bien, en Los sorias es el orden del "todo" lo que entra en guerra, el tejido maniqueo de la realidad laisequeana que entra en colisión: el Bien y el Mal, el Ser y el Anti-Ser, y, entre ambas fuerzas, esa malla porosa y ambigua que es el poder. Y si en el mundo mitológico de Laiseca el Bien y el Mal se enfrentan por medio de una magia militarizada y de los hombres que se enrolan en sus filas, es precisamente en el complejo ejercicio del poder donde se pone en juego lo humano: la deshumanización del dictador, atraído por el AntiSer, y su posterior salvación moral por gracia del Ser, es motivo dialéctico y obsesivo de la obra de Laiseca. Si en $L a$ mujer en la muralla se planteaba la deshumanización del tirano, en Los sorias se pone en juego el esquema narrativo inverso: la rehumanización del Monitor, líder de la Tecnocracia.

Más allá de las convenciones del género épico que entran en juego en su desarrollo narrativo, Los sorias se construye sobre ese enrarecimiento paródico y surrealista por medio del cual el realismo delirante genera su propia atmósfera: un ambiente enrarecido que Díaz Gavier denomina "tejido pop", en relación al pop art, y que a su vez vincula a lo que Walter Benjamin define como la "ebriedad revolucionaria" del surrealismo (2010, p. 1729). Si bien el espacio geopolítico construido en Los sorias busca la minuciosidad verosímil de un "universo aparte", proporcionando anclajes gráficos tales como mapas, esquemas y enumeraciones sistemáticas de costumbres, cultos, fuerzas militares, etc., nunca se instala en la exhaustividad "heterocósmica" de la fantasía épica o la ciencia ficción estandarizadas: lejos de la cartografía meticulosa de la Tierra Media de J.R.R. Tolkien, de la historiografía erudita del ciclo de Fundación de Isaac Asimov o de la intensiva ingeniería científica de Arthur Clarke, Laiseca se acerca más a esas épicas distorsionadas, barrocas y paranoicas de Thomas Pynchon o, más aún, al babélico reino onírico dirigido por el Gobernador Omnipresente de La otra parte (1909) de Alfred Kubin, novela fundacional del expresionismo alemán. El mundo de Laiseca flota entre el mito, el sueño y el delirio, y se distribuye en masas geopolíticas amorfas y desmesuradas, en espacios geográficos a veces arbitrarios (abundan los nombres absurdos de reinos o estados que no vuelven a ser mencionados), en una mixtura indesbrozable entre las referencias reales y las apócrifas, entre lo verosímil y lo sobrenatural, entre lo realista, lo fantástico y lo simbólico: ese "saber intransitivo" que definimos anteriormente para describir las claves principales de Aventuras de un novelista atonal.

Por su parte, Aichino (2011, p. 9) distribuye la narración de $L o s$ sorias en cuatro niveles:

1. El nivel cotidiano, donde se sitúa la apertura de la novela: Personaje Iseka vive en una pensión miserable junto a unos compañeros cuyos consejos 
interpreta como invasiones existenciales a su privacidad y a su inspiración artística. Cuando Iseka abandona la pensión, ubicada en una zona predominantemente Soria, para instalarse en la Tecnocracia, se abre el segundo nivel.

2. El nivel geopolítico: representado por las grandes potencias dictatoriales en guerra (Tecnocracia y Soria pactan alianzas con diferentes estados y llevan a cabo una guerra que Laiseca construye por medio de un pastiche de datos derivados de los grandes conflictos bélicos de la historia, poniendo énfasis en los personalismos fascistas de la II Guerra Mundial $\left.{ }^{11}\right)$. Esta guerra parece por momentos constituir una sublimación simbólica y extremada del enfrentamiento psicológico entre Personaje Iseka y sus "enemigos de pieza".

3. El nivel mágico: diversas sociedades esotéricas mantienen una guerra secreta, usualmente interpersonal (de mago a mago), y utilizan para ello dos armas: el conocimiento de la magia y los poderes de todo un bestiario de criaturas sobrenaturales que ellos mismos crean. Los enfrentamientos producidos en este nivel se corresponden, a su vez, a los del nivel geopolítico.
4. El nivel cosmológico: la eterna lucha entre el Ser (el Bien) y el Anti-Ser (el Mal), la cual tiene supeditados a sus avatares en los tres niveles anteriores.

Cabe destacar que, estos cuatro niveles que dan forma a $L o s$ sorias tienen un funcionamiento reversible: toda la guerra maniquea que sucede en el nivel cosmológico no sólo se expresa en los enfrentamientos esotéricos o en los geopolíticos, sino también en la psicología de los personajes. La rehumanización del Monitor, por ejemplo, se constituye en el eje profundo donde se debate el Ser y el AntiSer, razón por la cual no sería errado mencionar un quinto nivel: el nivel ético, donde el cosmológico encarna su mayor pugna por el alma del hombre. A su vez, este nivel se expresa en la forma en que Personaje Iseka percibe la guerra y en cómo ésta se erige en hipóstasis de sus conflictos psicológicos iniciales (los del nivel cotidiano). Y es en este nivel donde se emplaza uno de los temas fundamentales del realismo delirante: la sexualidad (en su versión laisequeana de lo "sadomasoporno"). En la vitalidad sexual de los personajes también se revelan los grandes enfrentamientos cosmológicos, y es usual que las utopías de Laiseca, como La hija de Kheops, encuentren en la sexualidad libre una vía para la humanización y la armonía espiritual (Aichino, 2011, p. 10).

También resulta necesario destacar que estos cuatro niveles no sólo se limitan a la narración de Los sorias, sino que se distribuyen de diversas maneras a lo largo de toda la obra del autor: así, por ejemplo, el nivel cotidiano predomina en la primera mitad de Aventuras de un novelista atonal, mientras que en su segunda mitad predomina una suerte de nivel mítico (donde se aúna el geopolítico y el mágico de Los sorias). Por su parte, la mayor parte de los cuentos de Matando enanos a garrotazos se ubica en el nivel geopolítico, aunque algunos, como "El checoslovaco", parecen centrarse en el nivel de los conflictos éticos (donde el cosmos maniqueo de Laiseca se encarna en la vida mental de los personajes). Por otra parte, las novelas exotistas de Laiseca (así como también Las cuatro torres de Babel y algunos relatos de Gracias Chanchúbelo) se producen en los cuatro niveles, sólo que el geopolítico, en lugar de tomar la apariencia de los fascismos contemporáneos de Los sorias, se encarna en la reconstrucción de ambientes y símbolos tomados de las civilizaciones antiguas.

\footnotetext{
11 Lo hiperbólico del realismo delirante alcanza también a la parodia de las jerarquías dentro de los regímenes dictatoriales (tanto en Soria como en Tecnocracia). Así, Laiseca mezcla el militarismo nazi con la burocracia soviética, resultado de lo cual es la abundancia de Monitorías y submonitorías, Kratos, secretarios, subsecretarios, vicesubsecretarios, infravice subsecretarios, etc.
} 
El jardín de las máquinas parlantes, novela que entra en diálogo constante con la obra mayor de Laiseca, desarrolla especialmente el universo del nivel mágico, que aparece representado en contrapunto con el cotidiano, el cosmológico y el ético. Si esta obra concentra en sí el mundo del esoterismo y la construcción de las criaturas mágicas tal como aparecerán en Los sorias, su nivel geopolítico se produce más bien de fondo: éste aparece apenas evocado, como una realidad fuera de foco, aunque con el mismo nivel de mixtura entre países reales y apócrifos (así, por ejemplo, la narración se sitúa en un espacio que, localizado en América del Sur, parece evocar directamente a la Argentina, aunque el estado se denomina Guatimotzín y su capital, equivalente a Buenos Aires hasta en los distorsionados nombres de las calles, se llama Tollán; aun así, a lo largo de la novela también se habla de Argentina, como si fuera un país distinto a Guatimotzín). En el caso de El jardin, la remisión a una realidad política inmediata es de las más explícitas que pueden encontrarse en la obra de Laiseca, y la figura de su dictador, Quetzal, comporta una parodia del tercer peronismo, incluyendo el regreso del exilio y la designación de un primer ministro maléfico que puede identificarse con López Rega.

La síncresis entre los diferentes niveles que se produce en
Los sorias lleva a su máxima expresión uno de los elementos fundamentales del realismo delirante: la descripción de las relaciones humanas y sus tensiones a través de metáforas bélicas. Los conflictos psicológicos entre Personaje Iseka y sus compañeros de pensión se distorsionan e hiperbolizan en la guerra geopolítica, manteniendo las claves en los nombres: el apellido Iseka es el que tienen todos los habitantes de la Tecnocracia y el de los hermanos Soria se amplifica hasta bautizar al estado homónimo: Soria. La creencia laisequeana en las energías psíquicas es una de las bases de su concepción de la magia, lo cual hace de su mundo un espacio donde la guerra es total en el sentido de abarcar desde los matices de los conflictos interpersonales hasta los enfrentamientos cósmicos entre el Ser y el Anti-Ser: de forma asfixiante y abarcadora, todo el universo de Laiseca participa de una misma guerra extendida en diferentes niveles. En El jardín de las máquinas parlantes, esta guerra entre el Bien y el Mal llega a las sutilezas más profundas de la vida mental: la guerra entre las diversas zonas del hombre, entre la luz y la oscuridad que cada uno alberga. Y esta dialéctica interior es la que, en su desarrollo narrativo más elaborado, permite el acceso al motivo de la deshumanización y la rehumanización del dictador.

En la cosmología de Los sorias, el lenguaje y el arte tienen una importancia radical, subordinada a fines esotéricos y religiosos. Es así que, dentro de la estructura estatal de la Tecnocracia, una de las monitorías más importantes es la de las Lenguas, dirigida por el Kratos Enrique Katel. En esta suerte de ministerio se investiga, entre otras cosas, el origen etimológico de las palabras, puesto que, "Según ellos, el Anti-Ser (o Dios del Mal) operaba sobre los hombres a través de las distorsiones idiomáticas" (p. 71). Las palabras, como símbolos del cosmos, invocan numerosos arquetipos. Conocer el origen de las palabras implica conocer a qué Dios se está invocando con ellas. Como ya se ve en $E l$ jardín de las máquinas parlantes, las guerras entre esoteristas, así como el funcionamiento de sus máquinas mágicas, están estrictamente ligadas al uso de las palabras y de las "manijas" (maldiciones) o salvaciones que estas producen en los hombres. A su vez, el Kratos de las Lenguas, a pesar de ejercer su actividad en el marco de una dictadura, posee una ideología estética representada positivamente a lo largo de la novela: de forma opuesta al rechazo tecnócrata frente a las formas artísticas experimentales o no comprometidas, Katel busca el advenimiento de un "nuevo arte" donde exista una libertad creadora absoluta. En este asunto, el Kratos y el Monitor mantienen constantes disputas. Aunque ambos acuerdan en lo que respecta a la libertad sexual, el Monitor rechaza profundamente 
las formas "sin trascendencia" del arte, como el arte abstracto o la música dodecafónica. En la dialéctica entre el Monitor y Enrique Katel, Laiseca representa su propio viraje desde el arte experimental de sus primeros textos hacia una literatura centrada en la invención novelesca $\mathrm{y}$ en una suerte de magisterio moral. Si tenemos en cuenta que la redacción de Los sorias es contemporánea parcialmente a Aventuras de un novelista atonal, puede comprenderse que la crítica al arte "atonal" todavía no sea tan radical como la que aparecerá en El jardín de las máquinas parlantes, donde el mismo personaje que defiende el "realismo delirante" critica los hermetismos vacíos y "sospechosamente inaccesibles" del arte experimental (2013, pp. 9798). En todo caso, la concepción laisequeana del arte se mantiene siempre en un equilibrio entre el entusiasmo de Katel por la vanguardia como forma de libertad creadora y la obsesión de Monitor por la trascendencia (lo cual lleva al dictador a denunciar la vanguardia por su frivolidad y falta de vitalidad).

Ahora bien, si Monitor representa la deshumanización del dictador extremista y fanático (cuya ulterior salvación adviene por la gracia de la derrota), Enrique Katel representa un discurso de mayor templanza y mesura. El viraje estético del propio Laiseca es puesto en boca del Kratos (significativamente, en una carta a Personaje Iseka, como si fuera una carta a sí mismo) del siguiente modo:

Usted declara ser escritor. Muy bien, entonces comprenderá si digo que en arte uno debe ser clásico pero al mismo tiempo futurista, innovador. Hace falta un gran criterio para no seguir un camino estético erróneo que conduzca a la esterilidad. A veces uno cree haber descubierto un planeta nuevo (una suerte de novela atonal, pongamos por caso), pero luego comprende años después que, pese a todos los hallazgos, es un camino cerrado [...] (p. 73).

Del mismo modo, Katel intenta atemperar el fervor y el odio de Personaje Iseka hacia los sorias (de quienes ahora sólo quiere vengarse por el tiempo que los toleró en la pensión): "Con quienes debemos ser implacables es con los sorias de espíritu" (p. 74), afirma Katel, y con ello diluye algunos de los matices ideológicos que eran centrales en la construcción semiológica del primer capítulo de la novela: si los sorias, especialmente en su encarnación inicial en Juan Carlos y Luis Soria ("los ene- migos de pieza"), pueden ser asociados connotativamente a una representación del "cabecita negra" provinciano, el discurso de Katel intenta redireccionar los atributos negativos de estos personajes hacia una interpretación más amplia, donde también los habitantes de la Tecnocracia (apellidados Iseka) pueden tener un espíritu "soria"12.

Equivalente al novelista atonal de Aventuras y al Corvina Sotelo de El jardín, Personaje Iseka, tal como nota el Kratos (p. 75), está "manijeado" e irremisiblemente destinado al fracaso y la locura, a no ser que encuentre un Maestro. La carta mesurada de Katel vendría a buscar la misma salvación espiritual que De Quevedo procura a Sotelo. Desde el punto de vista narratológico, si la función actancial del Sujeto se ve representada por Personaje Iseka y el del Oponente por los sorias en sus diversas manifestaciones, la función de Aliado estaría potencialmente encarnada por Enrique Katel, del mismo modo que en El jardín de las máquinas parlantes idénticas funciones se encarnan en: Sotelo (Sujeto), esoteristas chichis (Oponente) y De Quevedo (Aliado). En ambos casos, la función del Oponente oculta la acción del Anti-Ser y la del Aliado la del Ser. Podría decirse que la rehumanización

\footnotetext{
12 Frase que parece jugar con esa decadente expresión argentina que, procurando matizar el racismo y orientarlo hacia una cierta corrección política, afirma su rechazo a los "negros de mente, no de piel".
} 
final del Monitor representa en un nivel simbólico la salvación de Personaje Iseka y el triunfo del Ser, respectivamente.

La salvación (siempre salvación de la propia locura gracias a la asunción de la alteridad) configura una isotopía semántica axial y a la vez compleja dentro de la obra de Laiseca. Ya en El jardín de las máquinas parlantes, De Quevedo busca "desmanijear" a Sotelo alejándolo de sus obsesiones antisindicalistas, de sus experimentos artísticos vacíos $\mathrm{y}$, finalmente, de su irremediable soledad. En esta novela, durante la guerra teológica que se produce en el hospicio, Sotelo es parcialmente salvado del AntiSer por medio de una enseñanza contra el solipsismo (puesta en boca de un loco, pero en realidad proveniente de De Quevedo, que a su vez está poseído por el Ser): "Esto es parte de tu antiguo egoísmo: considerar a los otros como partes de tu persona en vez de verlos como lo que son: otros" (2013, p. 207). Significativamente, en Los sorias, el Kratos reflexiona de forma similar sobre la posible salvación de Personaje Iseka y, a la vez, elabora una crítica metaliteraria de gran densidad semiológica donde se ponen en duda dos procedimientos fundamentales del realismo delirante, a saber: la simbolización de la vida cotidiana como principio creador y la diseminación del "yo" del autor en diversos personajes. En este momento de la novela, la naturaleza simbólica o alegórica es expuesta como una zona blanda del realismo delirante, como aquello hacia lo que esta expresión literaria está siempre a punto de caer y que, aunque no cae en ello completamente, tampoco logra eludirlo. Enrique Katel, frente a una obsesiva carta anti-soria que le envía Personaje Iseka, piensa ${ }^{13}$ :

Que aquella invocación por medio de una carta era un suceso, por sus características, exactamente opuesto a los procesos internos de la novela simbólica alemana, donde todos los personajes son proyecciones del personaje principal: sus otras personalidades o "yoes", digamos. En esa novelística se parte del principio de que el alma humana contiene alturas excelsas, pero también aberraciones espantosas. Esta idea nace de la omnipotencia de su autor, que en el fondo cree contenerlo todo. Pero no es así. (2004, p. 75)

Con esto, Laiseca se refiere, de forma metaliteraria, a que el recurso de haber incluido una instancia dialógica en su novela (carta de Personaje Iseka y respuesta del Kratos, ambas con cosmovisiones diferentes) resulta un procedimiento contrario al de la novela simbólica germánica (probable referencia a Kafka y a Hesse), que se mantiene siempre en un registro monológico: personajes cuya diversidad esconde la voz singular del propio autor. Aún así, al criticar el recurso alegórico, Laiseca también denuncia su propia tendencia a la simbolización como principio creador. La reflexión de Katel continúa:

Esos escritores -meditó el Kratos-tienen muchísimos menos "yoes" de lo que se imaginan. A veces la fuerza no les alcanza ni para ser malos. Suponen ser niños terribles y resultan de lo más comunes. Arrancan del falso fundamento de que en el "teatro" de sus propias almas hallarán la purificación. Entonces todos los personajes y sucesos son símbolos y partes de un todo, que es el Gran Yo. ¡Vaya arrogancia! Esto resulta, cuanto menos, una falta de respeto por la realidad. El autor no es Dios ni cosa que se le parezca. Por creerse omnipotente olvida a los demás, deja de considerarlos seres humanos y los disminuye hasta hacerlos meros simbolos, simples propagaciones de su yo. El castigo viene solo, y es que

13 La cita es extensa, pero vale la pena incluirla debido a que en ella se concentran elementos fundamentales de la poética laisequeana y de las propias condiciones de producción de Los sorias. 
el escritor no resuelve su problema y patina en sus vicios hasta el último día de su vida: por no haber aceptado a los otros como otros. Una novela puede ser escrita por razones de purificación, y quizá muchos personajes contengan partes de su autor. Pero no todos, y aun los que entran en esta categoría, si son partes lo son entre otras cosas y a pesar de; lo más fructífero e importante, en todo caso, es el hecho de ser ellos mismos, pues viven.

Los simbolistas -continuó pensando con furia el Kratos- se parecen a quienes creen que el mundo no existe, que sólo ellos tienen resolución real y corpórea, y que están imaginando todos los procesos de la vida. En tal omnipotencia viciosa está la clave del fracaso: en su falta de respeto por el mundo terrenal.

Personaje Iseka había enviado a Enrique Katel una carta larguísima, ignoro cómo el otro tuvo paciencia de leerla. No se limitaba a referirle el asunto de los hermanos Soria, o el affaire yogur. Se explayó también sobre su vocación de escritor, en cómo había sido su proceso. Declaró que pensaba escribir una larga novela donde figu- rasen todos; una saga de purificación interior en la cual, etcétera, etcétera.

\section{$[\ldots]$}

De pronto tuvo una intuición, que bien podría ser falsa. Su entrenado olfato de Kratos de las Lenguas le hizo sospechar que Personaje Iseka debía ser uno de esos autores que en un pasado remoto estuvieron enganchados por el simbolismo alemán. Tales manijeados, a lo poco que han vivido en serio lo recortan de la realidad, lo incorporan a su novela simbólica y lo transforman en alegorías, ensuciando el hecho maravilloso de la existencia.

Si Personaje Iseka no bajaba de su altura falsamente poderosa, si no reconocía a la realidad como realidad y a los otros como otros, estaba frito. No tendría salvación. (pp. 75-76; el resaltado es nuestro)

El motivo de la salvación por medio del reconocimiento de la alteridad (tal como sucede con Sotelo en El jardín, gracias a su Maestro y a su amada Cecilia, o con los atonalistas en el relato "Los santos", que se salvan de su destino de soledad cuando abandonan su obra obsesiva y se marchan a hacer una familia y trabajar la tierra) se vincula estrictamente a la concepción de la propia obra: sólo respetando la especificidad de la realidad como fenómeno exterior y objetivo, el escritor se purifica y se salva de su locura. A su vez, estas reflexiones de Katel configuran una compleja puesta en escena de los mecanismos de la narrativa del autor, de sus puntos débiles, de sus contradicciones. La novela se pliega sobre sí misma, denunciando y condenando la propia instancia de enunciación que la hace posible. Incluso más: describe las características de una novela ideal y absoluta que, por un lado, parece representar lo opuesto de Los sorias, pero por otro, también expresa la voluntad profunda de la gran novela del autor:

Esperaba que ese tonto alguna vez escribiese algo que fuera superior a la novela simbólica alemana, con sus enfermedades y omnipotencias. Que escribiese una novela tal como una ciudad cuyas paredes, pisos y techos fuesen como enormes fotografías, cintas magnéticas y filmaciones de procesos internos y externos. Una novela al fin de la cual el lector, pese a todo, no se diga: "Esto lo soñó el personaje central", sino: "Ésta es una realidad, sucedió, los personajes viven y mueren en este libro, no hay símbolos que los ensucien. Se respetó su sangre". 
Si alguna vez el otro escribía su famosa novela, el Kratos rogaba para que su autor no cayese en la tentación de mancharla con símbolos, aunque ello exista siempre, aun si el hombre no se lo propone. La alegoría constantemente subyace; pero sólo los hombres reales y vivientes logran que el símbolo se comprenda, sin por ello permitir que invada el campo gravitatorio irrepetible de la vida.

Una novela que, aun partiendo del simbolismo alemán, éste termine por hacerse trizas. Sólo así su autor lograría purificarse en serio, pues ello sería prueba de que aprendió la dura lección. (p. 77)

Si este "hacerse trizas" remite en Los sorias a la disolución de los mecanismos solipsistas del criticado alegorismo, en Aventuras de un novelista atonal adquiere una concreta dimensión diegética: el novelista atonal, su novela y sus lectores se destruyen, como una forma de purificación. Paradójicamente, Laiseca hace decir al Kratos que el lector de esa novelamundo debe terminar la lectura sin pensar que todo lo sucedido fue un sueño del personaje protagonista. Sin embargo, y aunque no lo desarrollaremos aquí, puede decirse que existen numerosas y ambiguas claves en Los sorias para interpretar las guerras cosmológicas y deli-rantes entre Soria y Tecnocracia como un delirio compensatorio de Personaje Iseka (e incluso como un conjunto de fantasías oníricas). Es quizás por ello que Laiseca expresa la voluntad de clausurar (o al menos obsta-culizar) una clave hermenéutica que parecería desprenderse de la obra: la idea del delirio como sublimación psicológica. Personaje Iseka, según la concepción del autor, no debe ser comprendido como un centro significativo de la novela, del cual se desprenderían todos los personajes como hipóstasis diegéticas, sino que se debe juzgar el mundo narrativo por la realidad profunda que encubre bajo el manto de hiperbolización, anacronías y parodias. Así, el funcionamiento del poder, la violencia, el mal, el arte, el sexo -en fin, los grandes temas laisequeanos-, no son desprendimientos monológicos del autor, sino búsquedas dialécticas donde se representan formas opuestas de concebir el mundo (pensemos en la gran cantidad de debates dialógicos que alberga la novela en torno a diversas cuestiones, especialmente sobre el papel del estado en la vida del hombre) y cambios dinámicos en la estructura actancial de los personajes. Así, Monitor, al humanizarse y subjetivarse a lo largo de la novela, va adquiriendo de manera creciente una función como Sujeto central de la narración, alrededor del cual se construyen las demás funciones del relato.

\section{Conclusión}

La guerra, motivo obsesivo de la tradición literaria argentina, se disemina en Los sorias, de Alberto Laiseca, hacia la cons-trucción de todo un mundo posible. La guerra funciona en el realismo delirante, ya no como tema literario, sino como principio escriturario: una temporalidad mítica y una heterocósmica dispuesta en diversos niveles de representación cuyo eje es la guerra total como matriz narrativa. La guerra es el punto de partida para narrar, la base para estructurar tal narración y la justificación para poner en escena una mitología sustentada en un maniqueísmo filosófico cuya dialéctica se desplaza entre el Bien y el Mal, el Ser y el Anti-Ser.

Laiseca construye su obra capital a partir de la ambición de representar una guerra total (la guerra como símbolo de crisis cultural y como función textual donde, más que la remisión particularista a un específico fenómeno histórico, sobreviene la voluntad de mostrar lo bélico como atributo general, como figuración literaria de tensiones sociales). Y esta ambición se desplaza, a su vez, hacia dos grandes totalidades: la novela total - como superación del género por medio de la maximización de sus potencialidades episódicas y por su hiperbolización de lo novelesco como elemento plebeyo -y la obra de arte total- mezcla de géneros, aspiración artística autonomizada de lo exclusivamente literario. Pero también, esos niveles de totalidad acaban concentrándose en un único núcleo: la ética de un magisterio espiritual donde "lo total" (guerra, novela y arte) se convierten en la piedra de toque para la humanización del poder político. 


\section{Referencias}

Aichino, M.C. (2011). Enfrentamientos cósmicos en Los sorias, de Alberto Laiseca. Revista Digilenguas, 10, 6-11. Córdoba: Universidad Nacional de Córdoba.

Aichino, M.C. (2014). Teorías del fantástico y nuevos realismos. Reflexiones acerca de potenciales efectos de lectura en algunas obras de Alberto Laiseca y Marcelo Cohen. Recial, 5(5-6). Córdoba: Universidad Nacional de Córdoba.

Bergara, H. (2013). Plagios con un plagio de plagios. En: A. Laiseca. Por favor, iplágienme! (pp. 9-21). Buenos Aires: Eudeba.

Bonells, J. (Ed.) (2009). Dictionnaire des Littératures Hispaniques. París: Robert Laffont.

Casas, F. (2014). El aprendiz de brujo. Perfil.

De Arriba, M.L. (1996). Raras ficciones nuevas. CELEHIS: Revista del Centro de Letras Hispanoamericanas, 2(6-7-8), 243-253.

Dolezel, L. (1980). Truth and Authenticity in Narrative. Poetics Today, 1(3), 7-25.

Dolezel, L. (1999). Heterocósmica. Ficción y mundos posibles. Madrid: Arco/Libros.

Eco, U. (1992). Obra abierta. Buenos Aires: Planeta.

Estrade, C. (2013). Homo argentinus, homosexual, homo bellicum. Amerika, 8. doi: 10.4000/amerika.3867. Recuperado de http://amerika.revues.org/3867.

García, G. (1969). Los nombres de la negación. En: O. Lamborghini. El Fiord. Buenos Aires: Chinatown.

Holmes, A. (2008). China in Argentine Exotismo: Contemporary Inventions of the Orient. Bulletin of Spanish Studies, 85(1), 71-83.

Kohan, M. (2014). El país de la guerra. Buenos Aires: Eterna Cadencia.

Kurlat Ares, S. (2006). Para una intelectualidad sin episteme. El devenir de la literatura argentina (19741989). Buenos Aires: Corregidor.

Laiseca, A. (2011). Cuentos completos. Buenos Aires: Simurg.

Laiseca, A. (2013). El jardín de las máquinas parlantes. Buenos Aires: Gárgola.

Laiseca, A. (2003). Las aventuras del profesor Eusebio Filigranati. Buenos Aires: Interzona.

Laiseca, A. (2004). Los sorias. Buenos Aires: Gárgola.

Link, D. (1998). El gordo y el flaco. Radar.

Mazzuco, M. (2010, 24 de enero). Internet es un invento del príncipe de las tinieblas. La Gaceta Literaria (La Gaceta). Argentina: San Miguel de Tucumán. 
Molle, F. (2011, 5 de junio). Yo deliro pero con realismo. Perfil. Recuperado de http://www.perfil.com/ ediciones/cultura/Yo-delirio-pero-con-realismo-20116-578-0028.html.

Montaldo, G. (1990). Un argumento contraborgeano en la literatura argentina de los años '80 (Sobre C. Aira, A. Laiseca y Copi). Hispamérica (Gaithesburgh), 55, 105-112.

Petroselli, E. (2004). Televisión, literatura y terror en Buenos Aires. Ariadna rc, 22. Recuperado de http:// www.ariadna-rc.com/numero22/critica08.htm.

Piglia, R. (2004). La civilización Laiseca. En: A. Laiseca (1998). Los sorias (pp. 7-10). Buenos Aires: Gárgola.

Prieto, M. (2006). Breve historia de la literatura argentina. Buenos Aires: Taurus.

Ravetti, G. (2013a). Laboratório de ficção científica: Los Sorias, de Alberto Laiseca. Olho d'água, 5(1), 84-102.

Ravetti, G. (2013b). Os delírios testemunhantes de si, as conversões performáticas a propósito de Los sorias, de Alberto Laiseca. Letras de Hoje, 48(4), 512-520.

Sarlo, B. (2007). Escritos sobre literatura argentina. Buenos Aires: Siglo XXI.

Valles Calatrava, J.R. (2008). Teoría de la narrativa una perspectiva sistemática. Madrid: Iberoamericana.

Vázquez, C. (2008). La historia sin fin. Teína, 18. Recuperado de http://www. revistateina.es/teina/web/ teina18/lit3.htm.

Zunini, P. (2014, 24 de octubre). El libro de la guerra (entrevista a Martín Kohan). Eterna Cadencia. Recuperado de http://blog.eternacadencia.com.ar/archi ves/39728\#more-39728. 